\title{
ANALYSIS OF SUGAR MILL HEADSTOCK
}

\author{
Mr.Akshay Patil \\ Department of Mechanical Design Engineering, \\ RIT, Islampur, Maharashtra, India \\ Prof. M.M.Mirza \\ Department of Mechanical Design Engineering, \\ RIT, Islampur, Maharashtra, India
}

\begin{abstract}
Sugar mill plays important role in sugar industry it crushes the sugar cane to separate out the juice from sugar cane and sugar is made from juice. Headstocks are the parts of sugar mill. And they carry sugar mill rollers and trash plate assembly. All forces exerted by sugar mill rollers while working are come to mill headstocks. Hence mill headstock should sustain those forces without failure. Hence analysis of sugar mill headstock is necessary. So force exerted on sugar mill headstock due to hydraulic, power transmission by spur gears and dead weights are calculated by using force polygon diagram method. The boundary conditions are decided by considering working conditions and assembly of sugar mill. By making 3D model, static structural analysis of mill headstock is done by using Ansys software.
\end{abstract}

Keywords- Mill headstock, hydraulic forces, top cap, geometrical parameters

\section{INTRODUCTION}

Qugar cane is a grass of the genus Saccharum which is $\checkmark$ grown throughout tropical and subtropical regions, producing approximately 4000 lakh metric tons of raw sugar worldwide. The sugar mills are used to separate out the juice from the sugarcane. The extraction of juice in a mill is achieved by squeezing prepared cane between two rolls. In three roller mill three rollers are arranged in triangular pattern which are top roller, feed roller and discharge roller for removing sucrose $95-97 \%$. These rollers are fed by two pressure feeder rollers which take prepared cane from a vertical chute and may be assisted by an under feed roller at the exit from the chute. In the sugar mill one roller is placed at the top and two at the bottom and the position of each roller is adjustable in the mill headstock or mill housing. The sugar cane which is coming from the fibrizer is directly enter in mill and passes between the top and feed roller. That passage is large as compare to the gap between the top and discharge roller. Trash plate is used to give direction to sugarcane bagasse and placed between the feed and discharge rollers. It is mounted on the head stock and it is adjustable. The rollers are pressed together by hydraulic pressure, so the cane is compressed under rollers and the juice get separate from cane.
The hydraulic pressure is developed during milling depends on the layer of bagasse.

That hydraulic load is transferred and distributed to the Mill head stock in different sections. Mill head stock is a critical component amongst all. The forces acting on the mill headstock give rise to shearing, bending and compressive stresses. The mill head stock is most highly stressed.

\section{- $\quad$ working of sugar mill}

Firstly sugar cane pass from the fibrizer, where that cane is prepared by braking canes cells. After that prepared cane goes in sugar mill by using under feed roller which is mounted on the headstock at entry of sugar cane. The mills three working rollers are arranged in triangular form to squeeze prepare cane effectively. A trash plate is plate is placed between the feed and discharge roller to transfer the cane layer towards discharge roller. There is space between top roller and feed roller to pass the prepare cane similarly in between top roller and discharge roller, but this space is small as compare to feed and top roller space to increase the crushing rate.

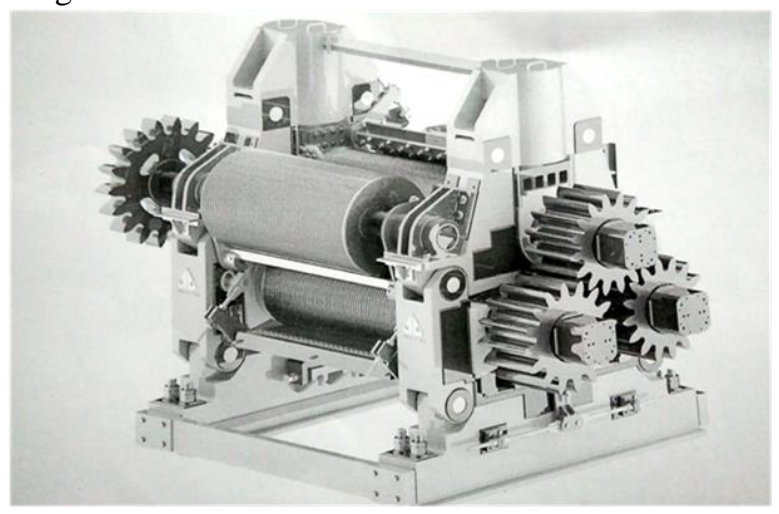

Fig. 1. Sugar roller mill

When the cane layer enters in mill it passes through the gap between the top and feed roller and so that layer push top and feed roller in the opposite direction. The top roller is assembled in such a way that it will float vertically. Movement top roller depends on thickness of cane layer. Hydraulic load is applied on top roller bearing to crush the 
cane. Hence, if cane layer thickness is increases then, the gap between the rollers also increase and if layer thickness is decrease the gap decrease.

The power is given to top roller by using motor to rotate it with feed and discharge roller. Top roller rotates the feed and discharge rollers by using spur gears. If the top roller is rotate in anticlockwise direction then feed and discharge roller rotates in clockwise direction. The speed of roller is in between 3 to $5 \mathrm{rpm}$.

\section{- Methodology}

This work has completed with the following action plan. In order to have successful completion of the work the action plane made as shown below:-

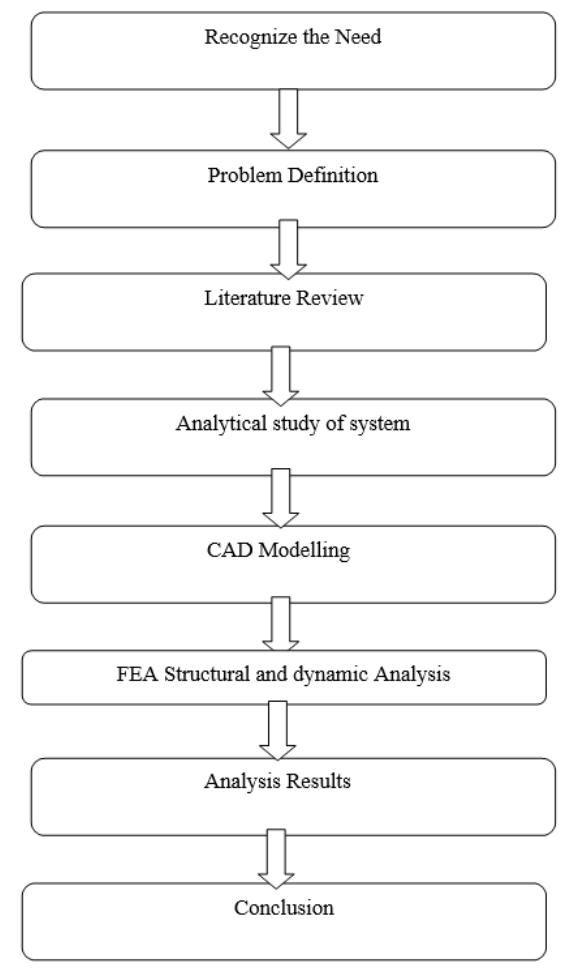

Fig.2. Flow chart of methodology

\section{LITERATURE REVIEW}

The present work is based on the studies carried out by various researchers on sugar mill. These papers are following

Yogini V. Deore et. Al. [1] She worked on FEA analysis and optimization of head stock used for Diameter $\Phi 50 " \mathrm{X}$ 100"Sugarcane Mill. She found shear stress and total deformation of the head stock by using ANSYS software and on the basis of the maximum share stress i.e. 125Mpa she reduced the thickness of the headstock by varying thickness values. She applied $50 \mathrm{kN}$ remote forces at each roller center. She found von Mises stress for original headstock is $2.9628 \mathrm{Mpa}$ whereas for headstock with $21 \mathrm{~mm}$ thickness is $92.545 \mathrm{Mpa}$. This is less than Maximum share stress value.
Santosh Y Salunkhe et. Al. [2] Presented Design and Analysis of Ø40" x 80" Conventional Sugar mill head stock. He has considered bending moment and force polygon diagrams in his theoretical study. Headstock is studied using static structural analysis and results are compared with theoretical results. This paper describes the advantages of using Ø40"X80" mill head stocks by designing \& analysis by ANSYS software. In his study theoretical study has been done considering the Bending moment \& force polygon diagrams. Bending moment factor which helps in finding actual results. He checked the strength of headstock against the hydraulic force. ANSYS software is used to calculate principal stresses, deformation of mill head stock.

R. R. Kartgi et. Al. [3] Presented Design And Analysis Of Roller Shafts For Sugar Cane Mills By Using FEA Technique With Different Parameters. The scope of this paper is to analyses the strength and hardness of the sugarcane roller shaft, which has the main contribution in the sugarcane industries. This paper deals with minimizing or reducing the effect of fatigue on the roller shaft. For minimizing the fatigue level, some parameters are considered, like over loading of bagasse, due to over loading of sugarcane in the cane milling, and the pressure is increased. For analyzing the strength of the material, load bearing capacity, material deformation, stress and thermal distribution in the roller shaft, ANSYS software is used and for designing PRO - E software is used.

C. Adam et. Al. [4] He worked on, The Effect of Blanket Thickness on Extraction Energy in Sugarcane Rolling Mills: a Finite Element Investigation. This study uses finite element methods to predict internal energy dissipation levels due to solid matrix deformation and liquid flow during rolling of prepared sugarcane, and to compare milling parameters for thick blanket, low speed rolling versus thin blanket, high speed rolling. The finite element results suggest that higher roll speeds and thinner blankets would maintain crushing rates and juice extraction levels while reducing roll load, torque, and power consumption, and decreasing frictional sliding between rolls and cane blanket. Energy dissipation during rolling of prepared sugarcane can be characterized in terms of four components; bulk plasticity, frictional sliding, juice flow, and seepage induced plasticity. Finite element simulations of a two-roll mill predict that frictional sliding does not occur until nip compression ratios of approximately 2.5 and roll surface speeds of $150 \mathrm{~mm} / \mathrm{s}$. At high compression ratios with normal blanket thickness, frictional sliding on the roll surface can comprise up to $20 \%$ of total power consumption, with significant implications for roll wear.

Rohit M. Chavan et Al. [5] He worked on Design and Analysis of Hydraulic Jack for Sugar Mill Setting in the three roller mil. The Hydraulic Jack System is Overcome the Demerits of old Mill Setting Arrangement. He has done the hydraulic jack component design by theoretical calculations and Analyze jack system by using ANSYS software. He calculated the stress by theoretical method and compared with stress calculated by analytical method. In This Case Solid Modeling of Required Vital Components are Done by him on Pro-e Software. The Components which he analyzed are Ram and 
Ram Cylinder, Ram Cylinder and Plunger Cylinder. Here the theoretical Stress Calculation is carried Out for Each Component. Then the Static Structural Analysis is carried for Every Component with the Help of ANSYS Workbench 15. In this Analysis the Calculated Parameters are Von Misses Stresses and Deformation. Finally he compared the Theoretical and Analytical Values with Each Other for Validation Purpose.

Shih-Liang (Sid) Wang et. Al. [6] He worked on Free Body Diagrams of Gear Trains. This paper gives several examples on different gear sets spur, helical, bevel, and worm gears and compound and planetary gear trains to determine the rotation direction of gears and force direction. Correctly drawn FBDs help the design of shafts (determining the shear force and bending moment) and bearings (determine the reaction force at bearings). In this case of gear ser and gear train three dimensional free body diagram are necessary and there are three type of forces acting on the gear while contacting with other gear and transmitting the torque or power 1] radial force, 2] tangential force, 3] axial force.

Shinde V. V et. al. [7]He worked on Weight Reduction and Analysis of Sugar Mill Roller Using FEA Techniques. He designed the shaft for input data Power $(\mathrm{P})=940 \mathrm{HP}$; Roller speed $=3.4 \mathrm{rpm}$; roller diameter $=1270 \mathrm{~mm}$. so he considered the hydraulic force (bagasse load) and forces acting on Gear during power transmission on the top roller. He designed the top roller shaft because the large amount of force is acting on the top roller because all input forces are given to top roller. He find out the bending moments and maximum stress acting on the shaft by theoretical method and FEA method also and compared hollow and solid shaft results with each other. He concluded that two sugar roller Mill with hollow shaft is preferable one and it offers much greater safety factors against failures.

\section{DISIGN CALCULATIONS}

\section{a) Hydraulic force calculations}

Input data of the mill headstock are as follows:-

1) Mill roller diameter(D) $=915 \mathrm{~mm}$

2) Mill roller length $(\mathrm{L})=1830 \mathrm{~mm}$

3) Design pressure $=280 \mathrm{~kg} / \mathrm{cm}^{2}$

4) Maximum design pressure $\left(P_{m}\right)=300 \mathrm{~kg} / \mathrm{cm}^{2}$

5) Hydraulic cylinder diameter $\left(D_{c}\right)=36 \mathrm{~cm}$

6) Apex angle of mill $(\Theta)=73^{\circ}$

As per E-Hugot, assumptions are as follows,

1) Discharge roller reaction is 0.8 of maximum design load

2) Feed roller reaction is five time less than discharge roller reaction.

3) Trash plate reaction is 0.25 times of maximum design load.

By force polygon diagram, following forces acting on Headstock.

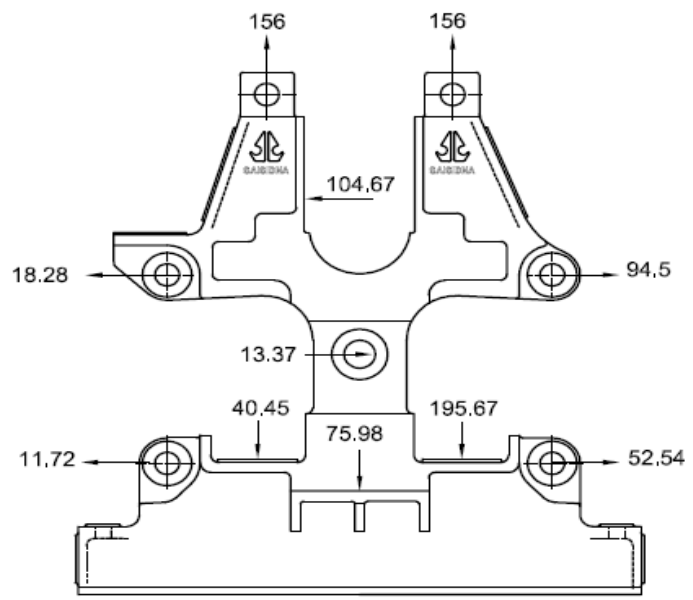

Fig.3. Mill headstock with hydraulic load details

\section{b) Torque Calculations}

Input data of the mill headstock are as follows:-

a) Motor power $=560 \mathrm{KW}$

b) Speed of rollers $=5 \mathrm{rpm}$

Power absorbed by sugar mill:

The determination of the power consumed by a mill is rather complex because a number of factors enter into it.

So we assume that power may be split up into five different principal terms:

(1) Power consumed by compression of the bagasse

(2) Power consumed in friction between the shafts and bearings of the rollers

(3) Power consumed by friction between bagasse and trash plate

(4) Power consumed by friction of scrapers and toe of the trash plate against the rollers, to which should be added the work of dislodging the bagasse at these points

(5) Power absorbed in the gearing.

By force polygon diagram, following forces acting on Headstock due to power transmission by using spur gear. 


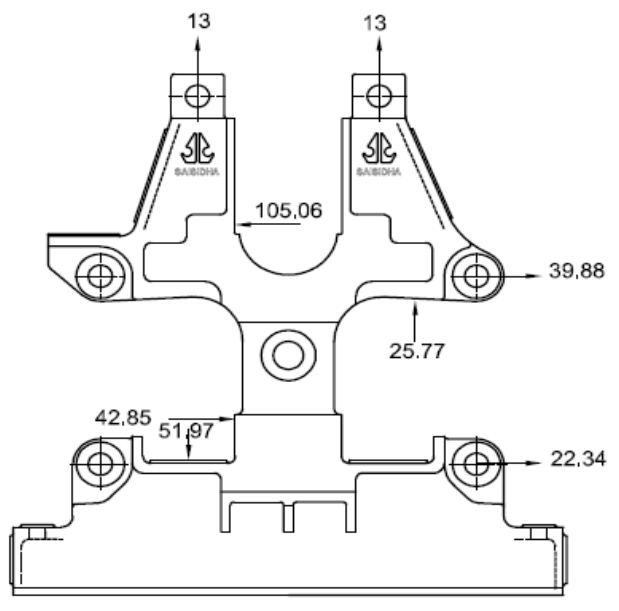

Fig.4 Mill headstock with torque load details

Dead weight calculations:

1) Top roller side total weight $\left(W_{t}\right)$ :

$\mathrm{T}_{\mathrm{t}}=$ Top roller weight $/ 2+$ Top Bearing weight + hydraulic jack assembly

$=20 / 2+0.5+4=14.5$ tons

2) Feed side total weight $\left(W_{f}\right)$ :

$\mathrm{T}_{\mathrm{f}}=$ feed roller weight $/ 2+$ feed side bearing weight + wedge weight $=20 / 2+0.4+0.6=11$ tons

3) Discharge side weight $\left(W_{d}\right)$ :

$\mathrm{W}_{\mathrm{d}}=$ discharge roller weight $/ 2+$ discharge side bearing weight + wedge weight

$$
=20 / 2+0.4+0.6=11 \text { tons }
$$

4) Trash beam weight on one headstock =trash assembly weight $/ 2$

$$
=8 \text { ton } / 2=4 \text { tons }
$$

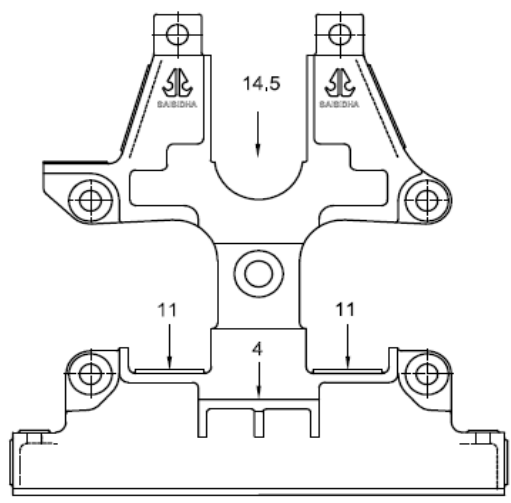

Fig.5. Mill headstock with dead weight details

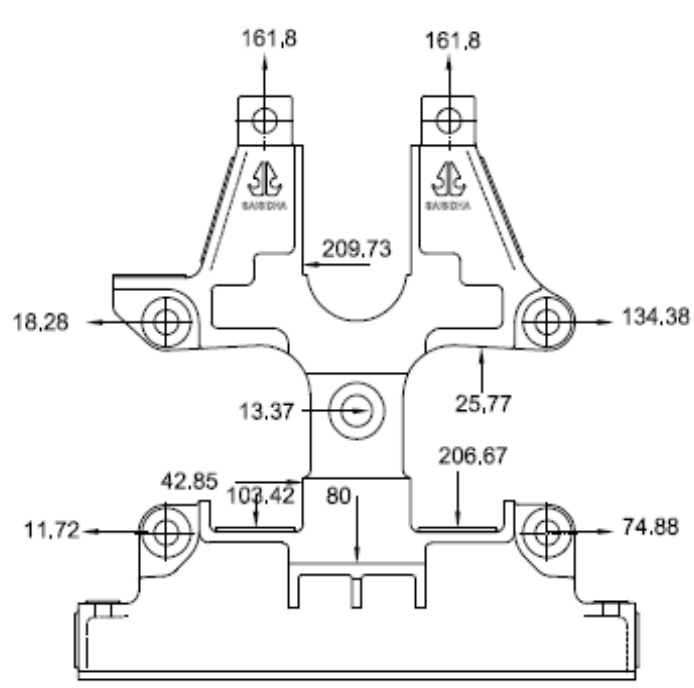

Fig.6. combination of forces acting on Headstock

\section{CATIA MODEL}

Headstock shape is designed by taking reference of mill roller arrangement and its height from foundation bed. The casting and machining design of sugar mill headstock are different but we want to check strength of machining design which is going to mount on foundation bed so I have done machining design model in catia v5 software.

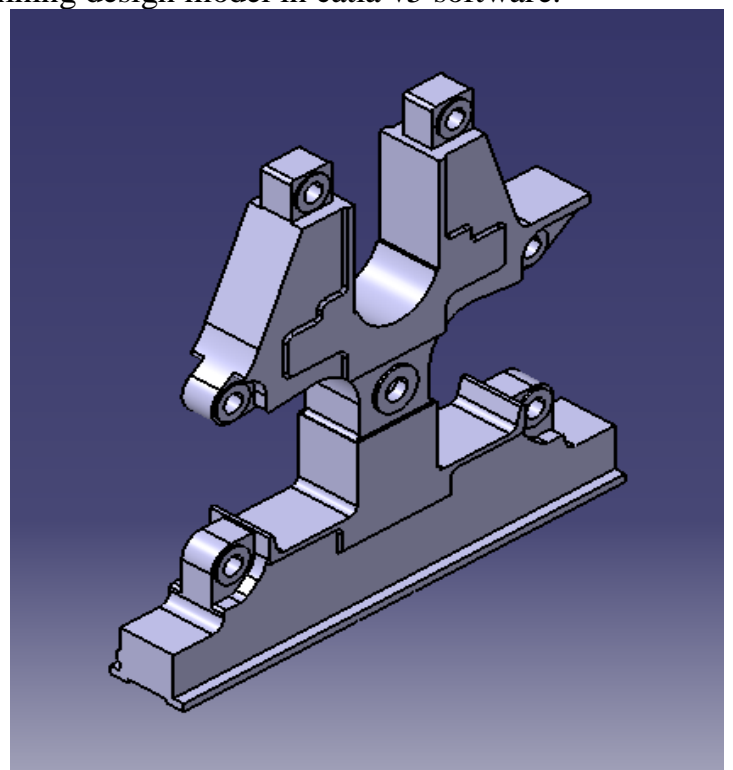

Fig.7. CATIA V5 model of Headstock

\section{FINITE ELEMENT ANALYSIS}

The sugar mill headstock is analyzed with the help of ANSYS software for his safe working by checking various parameters 
within limit and following are the results in ANSYS software in workbench.

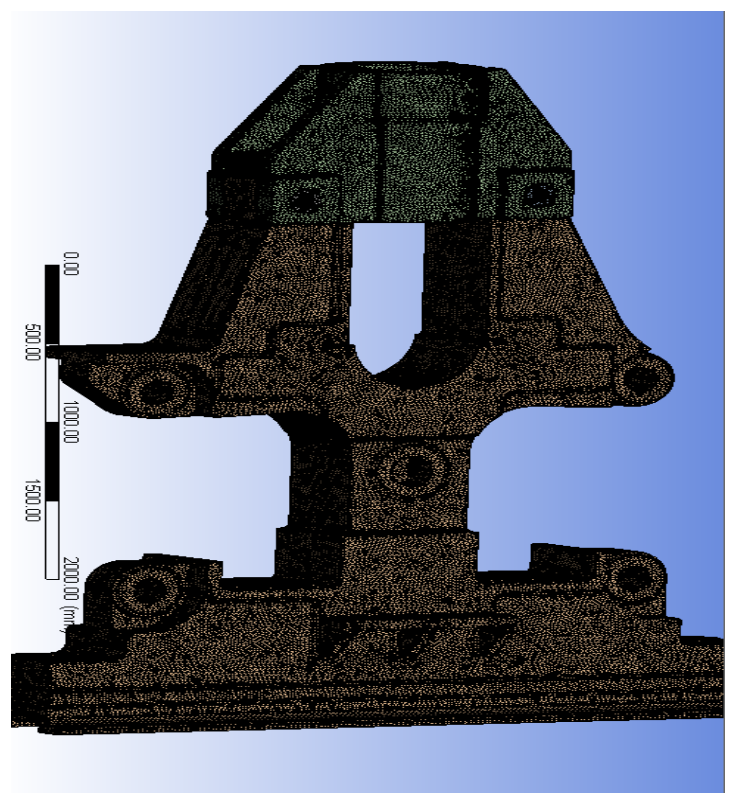

Fig.8. Mesh detail of sugar mill headstock.

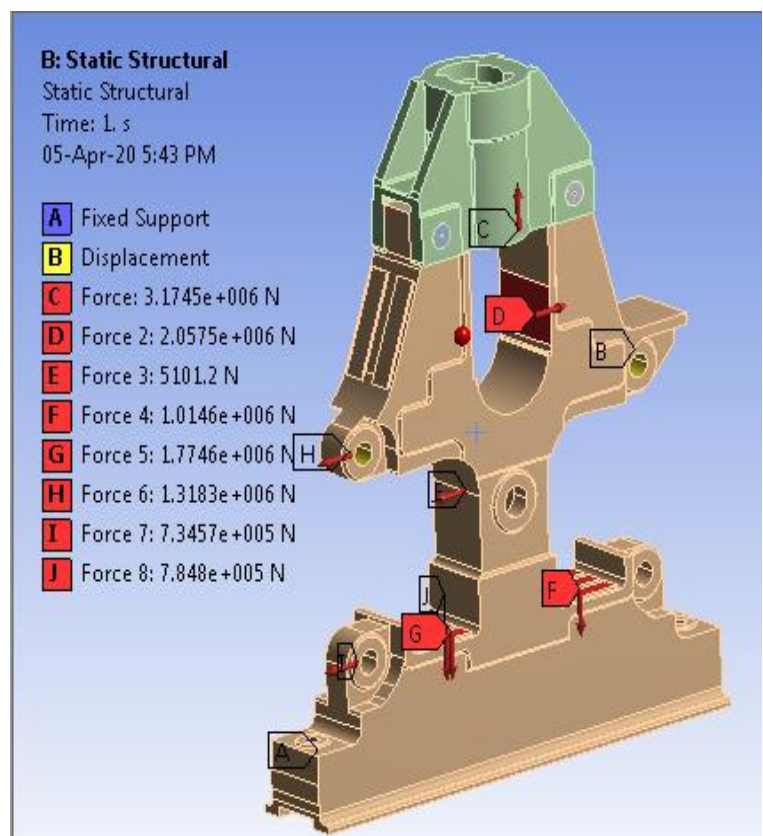

Fig.9. Static structure mill headstock with load details.

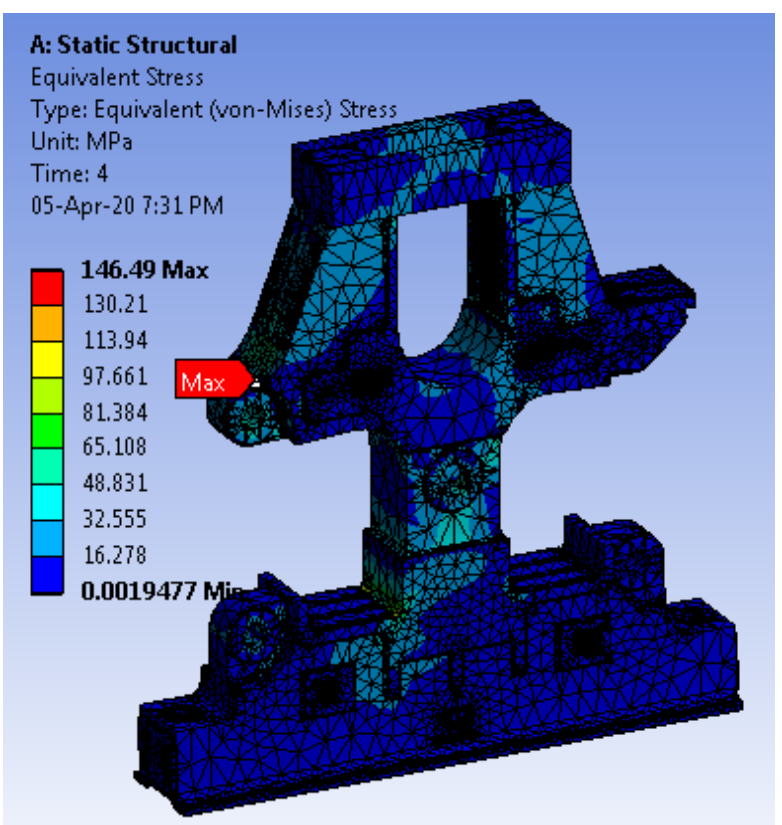

Fig.10. Von-mises stress in mill Headstock.

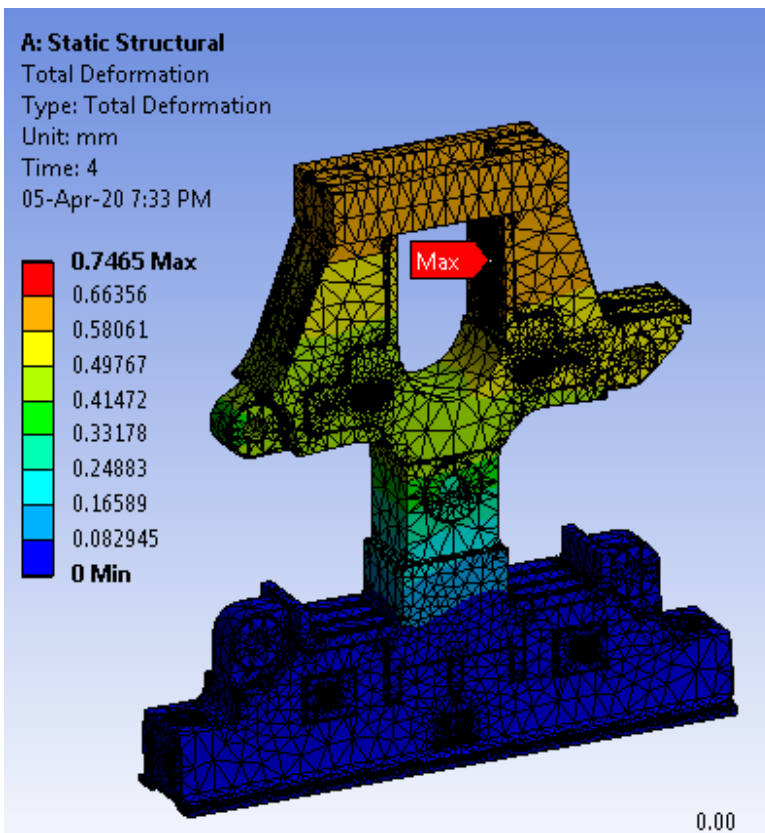

Fig.11. total deformation of Mill Headstock. 


\section{International Journal of Engineering Applied Sciences and Technology, 2020 \\ Vol. 5, Issue 5, ISSN No. 2455-2143, Pages 217-222 \\ Published Online September 2020 in IJEAST (http://www.ijeast.com)}

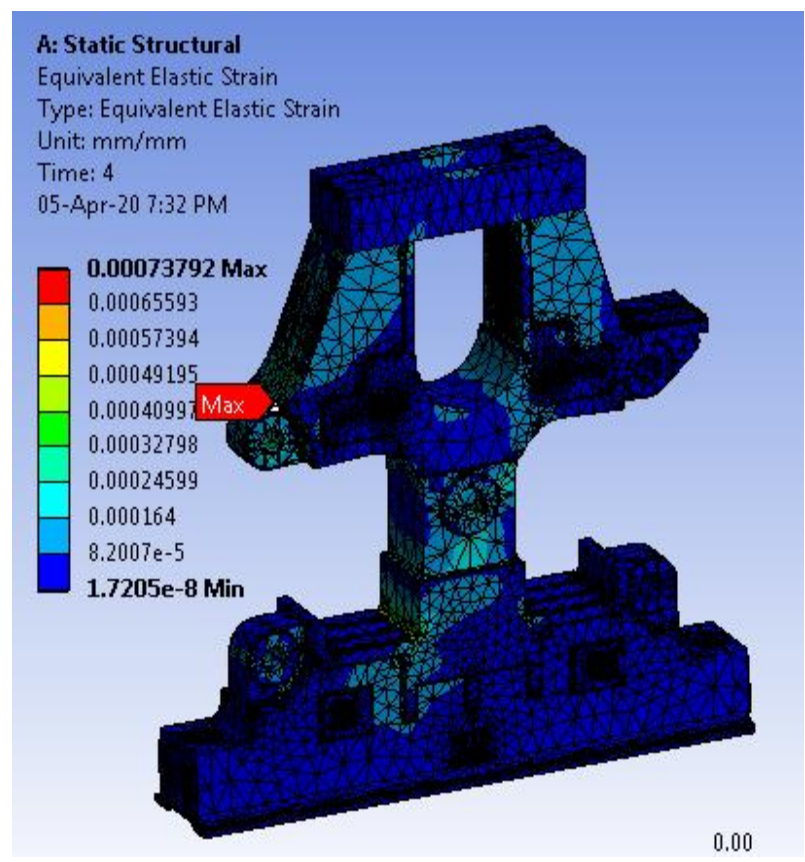

Fig.12. Elastic strain of mill Headstock.

\section{CONCLUSION}

Maximum stress observed on sharp edge of side cap mounting which is around $147 \mathrm{Mpa}$ which is less than yield strength ( $\mathrm{YS}=280 \mathrm{Mpa}$ ). Magnitude of maximum strain observed is 0.00076 and Maximum Deflection arrived at top baring housing which is $0.75 \mathrm{~mm}$. From above analysis results we can say that the sugar mill headstock is safe because the material yield stress is two times greater than the permissible stress value so the body is twice safer.

\section{REFERANCE}

[1] Salunkhe Santosh Y, (2015) "Design \& Analysis of Ø40" x Ø 80" Conventional Sugar mill head stock",International Journal of Scientific Engineering and Technology, ISSN :2277- 1581,Volume No.4 Issue No.7, pp: $397-$ 400.

[2] Chetan T Rathod, Walmiki S Rathod,( 2012) "Design and Analysis of Two Roller Sugar mill using FEA Techniques", International Journal of Scientific Engineering and Technology,(ISSN : 2277-1581), Volume No.1, Issue No.3, pg : 148-152.

[3] Rohit M. Chavan1, Prof. M. M. Mirza, R. Biradar,( 2017) “Design and Analysis of Hydraulic Jack for Sugar Mill Setting" International Journal of Engineering Research \& Technology , Vol. 4 Issue 05.

[4] E.Hugot (1986) Handbook of cane sugar engineering third edition, Elsevier science publishers.
[5] Design of Machine elements by V. B. Bhandari, 4th edition.

[6] S.M. Muzakkir, Harish Hirani, G.D. Thakre, M.R. Tyagi, "Tribological failure analysis of journal bearings used in sugar mills", Engineering Failure Analysis 18

[7] M. J. REID(1988),"Analysis Of The Causes Of Recent Roll Shaft, Failures In Natal Sugar", Proceedings of The South African Sugar Technologists' Association - June Sugar Milling Research Institute. 